\title{
The Effect of Different Estrus Synchronization Methods on Reproductive Performance in Laparoscopic Artificial Insemination Program in Morkaraman Sheep ${ }^{\#}$
}

\author{
Müzeyyen Kutluca Korkmaz ${ }^{1, a, *}$, Mustafa Yaprak ${ }^{2, b}$ \\ ${ }^{1}$ Department of Animal Science, Faculty of Agriculture, Malatya Turgut Ozal University, 44210 Malatya, Turkey \\ ${ }^{2}$ Department of Animal Science, Ataturk University, 25240 Erzurum, Turkey. \\ *Corresponding author
}

\begin{tabular}{|c|c|}
\hline R T I C L E I N F O & A B S T R A C T \\
\hline $\begin{array}{l}\text { Keywords: } \\
\text { Laparoscopic artificial insemination } \\
\text { Natural progesterone } \\
\text { Sheep }\end{array}$ & $\begin{array}{l}\text { This study investigated the reproductive performance, lamb survivability, and growing performance } \\
\text { of Morkaraman ewes, the estrus of which was induced by natural and synthetic progesterone and } \\
\text { which were inseminated by laparoscopic technique at the end of the mating season (December). In } \\
\text { the study, } 5 \text { different estrus synchronization methods (CIDR, Crestar, Natural progesterone, } \\
\text { Cronolone and MAP), } 100 \text { Morkaraman ewes, and lambs born to them were used. After the } \\
\text { completion of the estrus synchronization methods, the first sign of estrus was detected earliest in } \\
\text { the natural progesterone group ( } 39.53 \pm 1.87 \text { hours), and there was a significant difference between } \\
\text { the natural progesterone and vaginal sponges containing MAP and Cronolone concerning the time } \\
\text { to the first hour of estrus. Estrus rates were found significantly different across the study groups, } \\
\text { with the shortest time to estrus having been achieved by MAP. The lambing rates for CIDR, } \\
\text { Cronolone, Natural progesterone, MAP, and Crestar groups were } 74 \%, 61 \%, 56 \%, 33 \% \text {, and } 10 \% \text {, } \\
\text { respectively. There was no significant difference between the treatment groups concerning birth } \\
\text { weight, weight at various periods, and survivability of lambs although a significant difference was } \\
\text { found in their weaning weight. }\end{array}$ \\
\hline
\end{tabular}

Synchronization

CIDR

muzeyyen.korkmaz@ozal.edu.tr

(D)https://orcid.org/0000-0002-1542-7088|b@myaprak@atauni.edu.tr

http://orcid.org/0000-0002-6791-7273

(c) (1) () This work is licensed under Creative Commons Attribution 4.0 International License

\section{Introduction}

Synchronization of estrus in sheep and goats has been accomplished by shortening the luteal phase of the estrus cycle by PGF $2 \alpha$ or by lengthening it artificially by progesterone. In addition to the synchronization of estrus and regulating and promoting ovulation, hormone usage in female animals ensures obtaining uniform progeny at a given period of the year. There are several ways to control the estrus cycle in females using various applications like light manipulation, ram effect, progesterone, prostaglandin (PGF), pregnant mare serum gonadotropin (eCG), and gonadotropin-releasing hormone $(\mathrm{GnRH})$ (Koyuncu et al., 2019).

To induce ovarian activity in sheep and goats, progesterone containing solid medical silicones called progesterone-soaked sponges (FGA-fluorogestone acetate), (MAP-medroxyprogesterone acetate), and CIDR (controlled internal drug release) are widely used (Öziş Altınçelik et al., 2018).
Among artificial insemination methods, artificial cervical insemination using fresh sperm can achieve pregnancy rates of 40-60\%. However, problems associated with using thorough-paced rams and transporting fresh sperm have popularized frozen sperm. Nevertheless, birth rates achieved by frozen-thawed sperm are still not realistic. This is due to the unique structure of sheep cervix and the lack of an effective artificial insemination method. (Masoudi et al., 2017). Sheep cervix is highly convoluted and tortuous due to the presence of 4-7 cervical rings that point caudally providing a physical barrier to external contaminants (Shahat and Alsafy, 2009). Folds rings are fit into each other to close to cervix securely and provides barrier to transcervical artificial insemination (Prasad et al., 2020). Therefore, Australian researchers have developed a revolutionary technique called laparoscopic artificial insemination in sheep in 1982. Laparoscopy enables to traverse the abdominal wall through a mini-incision and 
allows artificial insemination and embryo transfer directly to the uterus (Gourley and Riese, 1990; Milovanović et al., 2013). However, laparoscopic artificial insemination has several disadvantages including high cost and requiring experience (Milovanović et al., 2013; Masoudi et al., 2017; Sathe, 2018).

This study was performed to assess the reproductive performance of Morkaraman sheep that underwent synchronization of estrus using natural and synthetic progesterone as well as the growth and developmental performance of the Romanov crossbreed lambs produced by a laparoscopic artificial insemination program.

\section{Materials and Method}

\section{Animal Material}

This study was conducted in November at the Research and Application Farm of the College of Agriculture, Atatürk University, Erzurum (39 $55^{\prime}$ N , 41 ${ }^{\circ} 17^{\prime}$ E, and 1820 $\mathrm{m}$ above sea level). The animal material of the study consisted of a total of 100 Morkaraman ewes aged 2-5 years randomly selected from a herd, which were evenly allocated to each group $(n=20)$ and homogeneous in terms of their body condition scores (2.5-3); Romanov rams were used as the sire for laparoscopic artificial insemination. Additionally, 10 vasectomized teaser rams were used to detect estrus in ewes after synchronization.

\section{Hormone Material}

In this research, CIDR (0.3 gr progesterone; Eaz1-Breed CIDR, Pfizer, New Zealand), Crestar (3 mg Norgestomet; solution for injection; $1.5 \mathrm{mg}$ Norgestomet in $1 \mathrm{ml}+2.5 \mathrm{mg}$ Estradiol Valerate, İntervet, France), $20 \mathrm{mg}$ Cronolone (Fluorogestone acetate, Chronogest $\AA \mathrm{CR}$, İntervet, France), $60 \mathrm{mg}$ MAP (Medroxyprogesterone acetate, Esponjavet, Hipra, Spain) and $60 \mathrm{mg}$ natural progesterone (Source Naturals, Natural Progesterone Cream, USA) were used to estrus synchronization while PMSG (Chronogest/PMSG, 6000 I.U., İntervet, France) was used to achieve multiple ovulation.

\section{Method}

Natural progesterone (Natural P4) obtained in creme form was soaked to sponges in a calculated amount of 60 $\mathrm{mg}$ and inserted into the vagina for 12 days. Sponges containing $20 \mathrm{mg}$ Fluorogestone acetate and $60 \mathrm{mg}$ medroxyprogesterone and CIDR were inserted to the vagina for 12 days; the ear implant (Crestar) (a cattle dose of $3 \mathrm{mg}$ was used in two divided doses) was placed under the ear skin with the help of a special applicator. In the Crestar group, $1 \mathrm{ml}$ injectable Crestar was administered intramuscularly. After the end of each application, 600 I.U PMSG was intramuscularly administered to all treatment groups. Following the completion of all applications, vasectomized teaser rams were added to each group, and estrus was checked. Ewes in estrus were underwent laparoscopic artificial insemination an average of 53 hours after the completion of the application.

Artificial insemination was performed by intrauterine insemination of both horns of the uterus with OviPro using 100 million spermatozoids per $0.4 \mathrm{ml}$ obtained by diluting Sperma collected with an artificial vagina from a threeyear-old ram. As the same ram and the same dose of sperm were used for all groups, the ram effect was not taken into consideration in data analysis. Vaginal electrical resistance was measured employing an estrus detector on the $0^{\text {th }}$ day and at the time of insemination to compare its effect on reproductive performance. An abdominal pregnancy test using Real-Time Ultrasound was performed on the $38^{\text {th }}$ day of gestation.

The ewes and the lambs were weighed and the lambs' birth weight was recorded 12-24 hours after delivery. Starting from the age of 1 week, all lambs were fed lamb starter feed started with 30 gr per day to reach 150-200 gr per day with daily increments of $30 \mathrm{gr}$; starting from the age of 15-20 days, all lambs were fed lamb grower feed 200-250 gr per day. The lambs' live weight was measured with a weighing scale every 15 days starting from birth until the 90th day. The lambs were weaned at the age of $60 \pm 5$ days.

\section{Statistical Analyses}

Reproductive performance, live weights of the lambs, and the relative effect of each factor affecting the lambs' characteristics were calculated with the least square's method and the MINITAB (2000) software package. Analysis of variance was used to determine the differences of the ewes' reproductive performance and Duncan Multiple Range Test was used to determine the significance of those differences (Düzgüneş et al., 1983).

\section{Results and Discussion}

\section{Estrus Rates}

The earliest time to onset estrus 24 hours after the treatment was in the natural P4 group; CIDR group; Crestar group; MAP group and Cronolone group, respectively (Table 1).

Figure 1 shows the relative distributions of the application techniques by the time to the occurrence of estrus. Figure 1 revealed that estruses emerged in the first 36 hours, with the Natural $\mathrm{P} 4$ group having a rate of estrus of approximately $35 \%$, which was followed by CIDR with a rate of estrus of about $25 \%$. The Crestar group having the lowest rate of estrus among the study groups also showed estrus in the first 36 hours. Estruses were found to aggregate mainly in the first 48 hours, with the Cronolone group reaching as high as $84 \%$ and the MAP group having an estrus rate of $15 \%$ only in the first 48 hours.

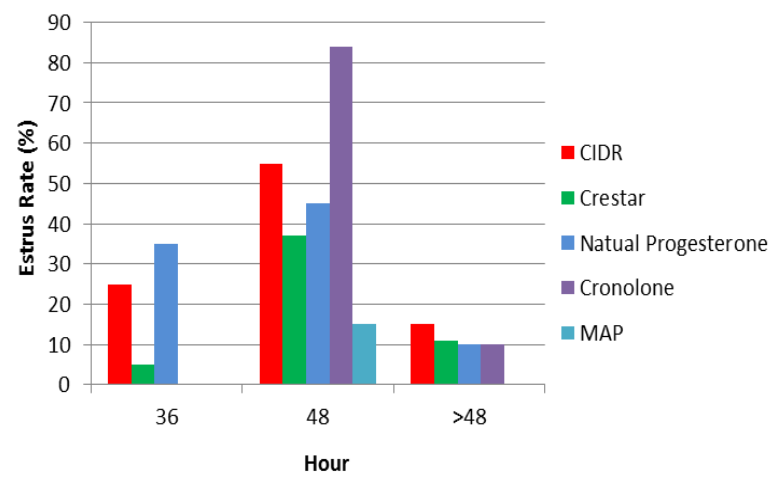

Figure 1. Distribution of estruses by the treatment groups 
The results regarding the rates of estrus showed that some of our values were similar to those reported by Üstüner et al. (2007) (38.18 \pm 4.7 hours) after the administration of FGA for 12 days whereas some of our values exceeded it. In the application groups except for the natural P4 group, the time to reach estrus was longer than 41.7 hours which was reported by Zeleke et al. (2005) and 29.5 and 26.3 hours which were reported by Macías-Cruz et al. (2013) whereas it was shorter than 69.6 hours which was reported by Godfrey et al. (1997). The results of the present study were similar to the duration of 42.2 hours reported by Emsen et al. (2008). Similarly, we noted a similarity with the results reported by Zonturlu et al. (2008) for FGA and CIDR and those reported by Kohno et al. (2005) for CIDR and progesterone cream.

The times from the termination of the applications to the time of estrus were longer than those reported by Fukui et al. (1999) for MAP, FGA, CIDR, and natural P4; however, the results of the present study supported the findings indicating that CIDR and Natural progesterone produced earlier signs of estrus.

Estrus checks performed 24 hours after the PMSG application revealed a markedly significant difference between the rates of estrus of the synchronization techniques $(\mathrm{P}<0.01)$. The results of the multiple range test for the estrus rate were given in Table 2.

In a study performed outside the mating season, $60 \mathrm{mg}$ medroxyprogesterone acetate (MAP) was administered for various durations such as 6,9 , and 12 days, and $75 \mu \mathrm{g}$ Dcloprostenol and 300 I.U. PMSG was administered intramuscularly one day after the sponges were removed. The estrus rates for 6,9 , and 12 days were $72.7 \% ; 72.7 \%$ and $80.0 \%$, respectively; the times from sponge removal to estrus were 46.0 hours; 31.0 hours, and 32.5 hours, respectively (Texeira et al., 2016). Our study revealed substantially lower estrus rates for MAP than that study but the time from the termination of the application to the time of estrus was similar. While the values of Ainsworth and Shrestha (1983), who reported that they detected the rate of estrus of $92 \%$ after 72 hours after sponge removal by synchronizing with FGA or MAP, were found similar to these values in the Cronolone group $(95 \%)$, the rate of estrus $(15 \%)$ in the MAP group was found lower than those reported by the above-mentioned researchers.

In a study where Pelibuey and Romanov X Pelibuey ewes were administered 140 ve 280 I.U. PMSG after vaginal sponge application, the rates of estrus by PMSG dose were $100 \%$ in both groups; the lambing rates were $70 \%$ and $73.7 \%$; and the number of lambs per viviparous ewe was 1.8 and 2.2 (Macías-Cruz et al., 2013). The lambing rates were similar in some groups but the number of lambs per viviparous ewe was lower in our study.

Although the values determined for the Cronolone and CIDR groups as a result of this study were similar to the estrus rates reported by Ungerfeld and Rubianes (2002) for MAP, $91.5 \%$ for FGA, and $91.5 \%$ for CIDR, the estrus rate obtained in MAP group animals was found to be lower than the results of the researchers. In another study, 400 I.U PMSG was administered at the end of the 5-day CIDR application; the rates of estrus within and outside the mating season were $94.5 \%$ and $94.3 \%$, respectively (Santos-Jimenez et al., 2020), which were in agreement with our results.

\section{Pregnancy Rates:}

The results of the abdominal pregnancy test performed 38 days after insemination in Morkaraman ewes inseminated with laparoscopic artificial insemination are presented in Table 2. The table indicates that the highest pregnancy rate was achieved by the CIDR group, followed by the descending order of Cronolone, natural P4, MAP and Crestar groups. Despite the marked differences between the pregnancy rates of some study groups, the differences between them were found statistically non-significant.

Pregnancy rates achieved by CIDR, Cronolone, and natural P4 were close to the rates reported by Berhan and Van Arendonk (2006) for Menz and Horro sheep and similar to the rate of $76.4 \%$ reported by Alaçam et al. (2001) at the insemination season. The present study achieved a pregnancy rate similar to that $(74.1 \%)$ reported by Godfrey et al. (1997) and that (75.3\%) reported by Cardwell et al. (2009) for CIDR; it also achieved similar pregnancy rate with that $(78 \%)$ reported with the use of progestagen+PMSG combination (G'omez et al., 2006). In a study where 600 I.U. PMSG was administered at the end of the vaginal sponge (30 mg Flurogestone Acetate) and CIDR (300 mg progesterone) application and where natural mating was used, the pregnancy rates were $91.67 \%$ and $83.33 \%$, respectively, and the number of lambs viviparous ewe were 1.40 and 1.30 , respectively (Murali Mohan, 2017). The lambing rate was found similar in the CIDR group.

\section{Lambing Rates}

Table 2 presents the calculated progeny yield characteristics in Morkaraman ewes that were synchronized with different methods and underwent laparoscopic insemination of freshly diluted spermatozoids containing 100 million motile spermatozoids per $0.4 \mathrm{ml}$. Table 2 indicates that the lambing rate was different between the application groups.

Emsen et al. (2008) reported a lambing rate of $33.3 \%$ after estrus synchronization using $30 \mathrm{mg} \mathrm{FGA}$ and 400 I.U. PMSG and laparoscopic artificial insemination at the end of the mating season. Compared with the related study, our CIDR, Cronolone, natural P4 applications achieved higher lambing rates; the Crestar group provided a similar rate, and MAP achieved a lower rate. Üstüner et al. (2007), at the time of mating of Karakaş sheep, achieved a lambing rate of $31.1 \%$ by short-term sponge application and cervical insemination and a lambing rate of $28.6 \%$ using long-term sponge application, with both rates being lower than the results of the present study.

\section{The Litter Size}

The litter size was not significantly different between different synchronization methods following the intramuscular administration of 600 I.U PMSG (Table 2).

The number of lambs per sheep was $100 \%$ in the MAP and Crestar groups, $110 \%$ in the natural $\mathrm{P} 4$ group, $118 \%$ in the Cronolone group and $129 \%$ in the CIDR group. Our lambing rate was lower than that $(161.4 \%)$ reported by Arsoy Başaran (1995) with sponge+600 I.U PMSG application in İvesi sheep. Reaching a lower lambing rate despite having used the same dose of PSMG may be explained by the physiological status of the sheep at the end of the mating season. 
Table 1. The mean of least squares, standard error, and multiple range (Duncan) test results of the time to the occurrence of estrus following the completion of the treatments.

\begin{tabular}{l|c}
\hline \multicolumn{1}{c|}{ Treatment Groups } & The earliest time to onset estrus (hours) \\
\hline CIDR & $42.41 \pm 1.82^{\mathrm{ab}}$ \\
Crestar & $45.46 \pm 2.50^{\mathrm{a}}$ \\
Natural P4 & $39.53 \pm 1.87^{\mathrm{ab}}$ \\
Cronolone & $47.47 \pm 1.87^{\mathrm{a}}$ \\
MAP & $46.86 \pm 4.57^{\mathrm{a}}$ \\
\hline Statistical Significance & $*$
\end{tabular}

a,b,c: The difference between the means tagged by different letters are significant; The difference between the means tagged by the same letter are nonsignificant, $*: \mathrm{P}<0.05$

Table 2. The mean of least squares, standard error, and multiple range (Duncan) test results of the reproductive performances of the synchronization methods.

\begin{tabular}{l|cccc}
\hline \multirow{2}{*}{\begin{tabular}{l|c} 
Treatment \\
\cline { 2 - 4 }
\end{tabular}} & $\begin{array}{c}\text { Estrus Rate } \\
\bar{X} \pm S_{\bar{X}}\end{array}$ & $\begin{array}{c}\text { Pregnancy Rate } \\
\bar{X} \pm S_{\bar{X}}\end{array}$ & $\begin{array}{c}\text { Lambing Rate } \\
\bar{X} \pm S_{\bar{X}}\end{array}$ & $\begin{array}{c}\text { Litter Size } \\
\bar{X} \pm S_{\bar{X}}\end{array}$ \\
\hline CIDR & $0.95 \pm 0.077^{\mathrm{a}}$ & $0.74 \pm 0.110$ & $0.74 \pm 0.108^{\mathrm{a}}$ & $1.29 \pm 0.129$ \\
Crestar & $0.53 \pm 0.079^{\mathrm{b}}$ & $0.30 \pm 0.151$ & $0.10 \pm 0.149^{\mathrm{b}}$ & $1.00 \pm 0.481$ \\
Natural P4 & $0.90 \pm 0.077^{\mathrm{a}}$ & $0.61 \pm 0.113$ & $0.56 \pm 0.111^{\mathrm{b}}$ & $1.10 \pm 0.152$ \\
Cronolone & $0.95 \pm 0.079^{\mathrm{a}}$ & $0.72 \pm 0.113$ & $0.61 \pm 0.111^{\mathrm{a}}$ & $1.18 \pm 0.145$ \\
MAP & $0.15 \pm 0.077^{\mathrm{c}}$ & $0.33 \pm 0.275$ & $0.33 \pm 0.272^{\mathrm{bc}}$ & $1.00 \pm 0.481$ \\
\hline Significance Level & $* *$ & $\mathrm{~ns}$ & $*$ & $\mathrm{~ns}$ \\
\hline
\end{tabular}

a,b,c: The difference between the means tagged by different letters are significant; The difference between the means tagged by the same letter are nonsignificant, ${ }^{*}: \mathrm{P}<0.05 ; * *: \mathrm{P}<0.01 ;$ ns: non-significant

Table 3. The mean of least squares, standard error, and multiple range (Duncan) test results of the progeny yield characteristics of vaginal electrical resistance values at the start of the application.

\begin{tabular}{l|cccc}
\hline Vaginal Electrical Resistance (ohm) & $\begin{array}{c}\text { Estrus Rate } \\
\bar{X} \pm S_{\bar{X}}\end{array}$ & $\begin{array}{c}\text { Pregnancy Rate } \\
\bar{X} \pm S_{\bar{X}}\end{array}$ & $\begin{array}{c}\text { Lambing Rate } \\
\bar{X} \pm S_{\bar{X}}\end{array}$ & $\begin{array}{c}\text { Litter Size } \\
\bar{X} \pm S_{\bar{X}}\end{array}$ \\
\hline $10-20$ & $0.44 \pm 0.153$ & $0.50 \pm 0.250$ & $0.25 \pm 0.252$ & $2.00 \pm 0.463$ \\
$21-30$ & $0.69 \pm 0.115$ & $0.64 \pm 0.151$ & $0.64 \pm 0.152$ & $1.14 \pm 0.175$ \\
$31-40$ & $0.65 \pm 0.072$ & $0.65 \pm 0.098$ & $0.54 \pm 0.099$ & $1.21 \pm 0.124$ \\
$41-50$ & $0.77 \pm 0.098$ & $0.65 \pm 0.122$ & $0.65 \pm 0.122$ & $1.18 \pm 0.140$ \\
$>50$ & $0.91 \pm 0.138$ & $0.50 \pm 0.158$ & $0.40 \pm 0.160$ & $1.00 \pm 0.231$ \\
Significance Level & $\mathrm{ns}$ & $\mathrm{ns}$ & $\mathrm{ns}$ & $\mathrm{ns}$ \\
\hline
\end{tabular}

ns: non-significant

Table 4. The mean of least squares, standard error, and multiple range (Duncan) test results of the effects of the synchronization techniques on vaginal electrical resistance values at the time of insemination.

\begin{tabular}{l|c}
\hline \multicolumn{1}{c|}{ Treatment } & Vaginal electrical resistance values at the time of insemination \\
\hline CIDR & $266 \pm 20.83$ \\
Crestar & $308 \pm 28.71$ \\
Natural P4 & $253 \pm 21.40$ \\
Cronolone & $223 \pm 21.40$ \\
MAP & $207 \pm 52.43$ \\
Significance Level & $\mathrm{ns}$ \\
\hline ns: non-significant &
\end{tabular}

Table 5. The mean of least squares, standard error, and multiple range (Duncan) test results of the effects of the vaginal electrical resistance values on progeny yield at the time of insemination

\begin{tabular}{l|ccc}
\hline \multicolumn{1}{c|}{ Vaginal Electrical Resistance } & Pregnancy Rate & Lambing Rate & Litter Size \\
& $\bar{X} \pm S_{\bar{X}}$ & $\bar{X} \pm S_{\bar{X}}$ & $\bar{X} \pm S_{\bar{X}}$ \\
\hline $15-20$ & $0.67 \pm 0.126$ & $0.60 \pm 0.129$ & $1.22 \pm 0.159$ \\
$21-25$ & $0.70 \pm 0.089$ & $0.60 \pm 0.091$ & $1.17 \pm 0.112$ \\
$26-30$ & $0.50 \pm 0.141$ & $0.58 \pm 0.144$ & $1.29 \pm 0.180$ \\
$>30$ & $0.45 \pm 0.148$ & $0.27 \pm 0.150$ & $1.00 \pm 0.275$ \\
Significance Level & $\mathrm{ns}$ & $\mathrm{ns}$ & $\mathrm{ns}$ \\
\hline
\end{tabular}

ns: Non-significant 
Table 6. The mean of least squares, standard error, and multiple range (Duncan) test results of the live weights of the lambs at various periods

\begin{tabular}{|c|c|c|c|c|c|c|c|c|}
\hline Factors & $\begin{array}{l}\text { rthweight } \\
\text { (kg) }\end{array}$ & $\frac{30 \text { th day W. }}{(\mathrm{kg})}$ & $\frac{45 \text { th day W. }}{(\mathrm{kg})}$ & $\frac{\text { 60th day W. }}{(\mathrm{kg})}$ & $\begin{array}{c}\text { 75th day W. } \\
(\mathrm{kg})\end{array}$ & $\frac{90 \text { th day W. }}{(\mathrm{kg})}$ & $\frac{\text { Weaning W. }}{(\mathrm{kg})}$ & $\begin{array}{c}\text { Weaning age } \\
\text { (days) }\end{array}$ \\
\hline \multicolumn{9}{|c|}{ Synchronization Type } \\
\hline IDI & 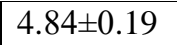 & .21 & 721 & 1 & $5.81 \pm$ & 19 & 15 & ( \\
\hline P4 & 5 & 10 & & 14. & 18.8 & & & \\
\hline \multirow[t]{2}{*}{ Cronolone } & $96 \pm 0.249$ & $10.91 \pm 0.744$ & $13.65 \pm 0.908$ & $15.26 \pm 0.447$ & $17.87 \pm 0.594$ & $18.10 \pm 0.669$ & $14.97 \pm 1.306^{\mathrm{a}}$ & $65.14 \pm 2.11$ \\
\hline & ns & ns & $n c$ & ns & ns & $n s$ & * & ns \\
\hline \multicolumn{9}{|c|}{ Sex } \\
\hline $\mathrm{ma}$ & & & & $.72 \pm 0.323$ & 1 & & & \\
\hline \multirow[t]{2}{*}{ Male } & $24 \pm 0.209$ & $10.87 \pm 0.609$ & $12.69 \pm 0.758$ & $14.81 \pm 0.386$ & $17.82 \pm 0.551$ & $18.48 \pm 0.515$ & $13.37 \pm 1.104$ & $63.57 \pm 1.78$ \\
\hline & ns & ns & ns & $\mathrm{ns}$ & ns & 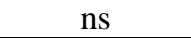 & $m_{0}+2$ & ns \\
\hline \multicolumn{9}{|c|}{ Birth Type } \\
\hline & & $11.74 \pm 0$ & $.56 \pm$ & $02+0$ & $.58 \pm$ & & & ה \\
\hline \multirow[t]{2}{*}{ Twin } & $8 \pm 0$ & $9.71 \pm 0$. & $6 \pm 0.911^{b}$ & $14.51 \pm 0.462$ & \pm 0 . & & & $68.28 \pm 2.00$ \\
\hline & & & r & ns & ns & $*$ & $* *$ & \\
\hline
\end{tabular}

a,b: The difference between the means tagged by different letters are significant; The difference between the means tagged by the same letter are nonsignificant**:P<0.01; *: $\mathrm{P}<0.05$, ns: Non-significant, W: Weight.

Table 7. The mean of least squares, standard error, and multiple range (Duncan) test results of survival rates of lambs at various time periods

\begin{tabular}{|c|c|c|c|c|c|c|c|}
\hline \multicolumn{8}{|c|}{ th DSR (\%)90th DSR (\%) Survival rate at W (\%) } \\
\hline \multicolumn{8}{|c|}{ Synchronization Type } \\
\hline CIDR & 89.6 & 89.6 & 89.5 & 89.5 & 72.8 & 72.8 & 89.5 \\
\hline Natural P4 & 97.9 & 97.9 & 88.4 & 88.4 & 75.6 & 75.6 & 88.4 \\
\hline Cronolone & 92.6 & 92.6 & 92.1 & 92.1 & 69.6 & 69.6 & 92.1 \\
\hline \multicolumn{8}{|c|}{$\mathrm{ns}$} \\
\hline \multicolumn{8}{|c|}{ Sex } \\
\hline Female & 87.1 & 87.1 & 86.2 & 86.2 & 81.4 & 81.4 & 86.2 \\
\hline Male & 99.6 & 99.6 & 93.8 & 93.8 & 64.0 & 64.0 & 93.8 \\
\hline \multicolumn{8}{|c|}{$\mathrm{ns}$} \\
\hline \multicolumn{8}{|c|}{ Birth Type } \\
\hline Single & 96.9 & 96.9 & 92.6 & 92.6 & 80.1 & 80.1 & 92.6 \\
\hline Twin & 89.8 & 89.8 & 87.4 & 87.4 & 65.3 & 65.3 & 87.4 \\
\hline \multicolumn{8}{|c|}{ ns } \\
\hline
\end{tabular}

ns: non-significant, DSR: Day Survival Rate, W: Weaning

Vaginal Electrical Resistance (VER) Values of the Ewes

Recently, more emphasis has been placed on more practical methods than hormonal analysis for determining the most accurate time of insemination. Among these, indirect measurements closely related to the hormone profile of the ewes are the main ones. Electrical resistance is one of the most reliable measurements of the vagina, the organ that reflects the effects of blood hormones on estrus, ovulation, and pregnancy. As stated before, there is a negative correlation between vaginal electrical resistance (ER) and blood estrogen level, and a positive correlation between the VER and blood progesterone level. In the present study, the VER values were taken just before the application of the estrus synchronization methods and at the time of insemination. Irrespective of the estrus synchronization methods, the effect of VER on the rate of estrus was found statistically non-significant. Previous studies have reported that VER is about $30 \mathrm{Ohm}$ at the time of ovulation (Emsen and Gimenez Diaz, 2008).

Table 3 indicates that the highest rate of estrus $(91 \%)$ was obtained for VER values above $50 \mathrm{ohms}$ although the difference was statistically non-significant. Because, when VER is positively correlated to progesterone and increased, progesterone level showed a parallel increase, it may be concluded that the effect of exogenously administered progestagen was augmented, resulting in a higher rate of estrus.

Although the effect of estrus synchronization preparations applied with different source, time, and combinations on VER values measured at the time of insemination was statistically non-significant, some values were higher than the others (Table 4). This can be explained by a different mode of action of each technique on the estrus cycle. Likewise, the progesterone source in the long-term applications differed in the form of first (MAP) and third (Cronolone) generation synthetic and natural progesterone.

Despite the absence of any significant difference concerning the VER value at the time of insemination, the ideal VER value in terms of pregnancy and lambing rates was $21-25 \mathrm{ohm}$ (Table 5). A comparison of these values with the reference values led to the conclusion that the animals were inseminated before ovulation. The inseminations performed above the reference value of 30 ohms for ovulation yielded the lowest pregnancy rate, lambing rate, and the number of lambs per viviparous ewes. 
Birth weights, Weights at Various Periods, Weaning Weights, and Survivability Characteristics of the Lambs Birth Weight

In this study, single birth occurred to only one ewe each in the Crestar and MAP groups, which were not included in the lamb growth analyses due to the too-small sample size. The results of the multiple range test of the lambs' birth weight, weaning weight, and weights at various periods were given in Table 6 .

Birth weight, a marker of an ewe's productive power, was found $4.84 \mathrm{~kg}$ in the CIDR group, $5.25 \mathrm{~kg}$ in the natural progesterone group, and $4.96 \mathrm{~kg}$ in the Cronolone group. The synchronization type, sex, birth type, and the ewe's weight at the time of delivery had no significant effect on birth weight. Although birth weight was not significantly different across the study groups, a slight difference was observed originating from the CIDR and Cronolone groups having lower birth weights, where multiple births concentrated.

A sex-based comparison of birth weight revealed that in the present study, as many other studies, male lambs were born with a greater birth weight by a margin of 450 gr. However, female lambs had a greater live weight than male lambs at certain time points in the later stages of the study.

30th, 45th, 60th, 75th And 90th-Day Weights of the Lambs

Lower live weight in the CIDR and Cronolone groups due to the concentration of multiple births in those groups subsequently caught up the mean weight of the lambs in the natural $\mathrm{P} 4$ group having a higher mean birth weight within one month.

A review of Table 6 shows that particularly birth weight and birth type had a profound effect on 30th-day weight. Although no significant difference was found between both sexes concerning 30th-day weight, the $2.03-\mathrm{kg}$ difference between twin and single born lambs was found statistically significant. The inter-sex difference between live weights disappeared on the 60th and 75th days and the live weights became equal. Live weight was in favor of single born lambs on 60th day (single born $15.02 \mathrm{~kg}$; twin born 14.51 $\mathrm{kg}$ ) but it turned in favor of twin-born lambs with a margin of 500 gr on 75 th day. It may be concluded that the shifting balance between both sexes and birth types from time to time is a result of the degree of benefiting from the lamb starter diet which was introduced after the first week of life and the lamb grower diet and fodder which were introduced after 15 th day of life.

When it comes to 90th-day weight, it was observed that the preceding live weight had a markedly significant effect $(\mathrm{P}<0.01)$ and the birth type had a significant effect $(\mathrm{P}<0.05)$, as in the other periods.

\section{Weaning Weight}

Different researchers have reported that weaning at the age of 4-6 weeks would cause no decline in lamb growth. It has been stressed that some other criteria besides age are also important for determining the weaning time of lambs. It was reported that lambs can be weaned when they reach $12-13 \mathrm{~kg}$ or 3-4 times their birth weight, and what the important is that the lambs grow enough to consume enough feed to meet their nutrient needs (Altın et al., 2003).

In the present study, the lambs in the whole group were weaned on average 65 th day. A review of Table 6 indicates that birth weight and birth type had a markedly significant effect $(\mathrm{P}<0.01)$ and the synchronization type had a significant effect on the weaning time $(\mathrm{P}<0.05)$.
The weaning weights in this study for each of the three application groups were higher than that $(13.81 \mathrm{~kg})$ achieved by intravaginal sponge application (Emsen, 2002) and that $(15.5 \mathrm{~kg}$ ) achieved by Atsan et al. (2007) for native breed lambs born after FGA+PMSG application and weaning on 75th day. On the other hand, the present study revealed a lower weaning weight when compared to a weaning weight of $21.8 \mathrm{~kg}$ found by Aslan (2008) in Romanov $\times$ Morkaraman crossbreed lambs.

Although it is determined that the effect of synchronization type on weaning weight is important in statistical analysis results, it should be kept in mind that environmental conditions, care and feeding conditions have a more important effect on the live weight of lambs after birth. It is believed that synchronization types may only affect birth weight, which likely results from multiple pregnancies they produce. Hence, low weights recorded in a given group should not be related to the synchronization method of the group, but environmental conditions should be focused more closely, as stated above.

Survivability Characteristics of Lambs

The multiple range test results of the survivability characteristics of the lambs are shown in Table 7. Table 7 revealed that the synchronization technique, sex, and birth type had no significant effect on survivability characteristics studied from the 15th day to the 90th day. Likewise, there was no significant effect on survivability characteristics at the time of weaning.

The survivability characteristics at different periods presented in Table 7 revealed that lamb deaths occurred within the first 15 days after birth, which is a critical period for lambs, and survivability remained stable thereafter until the 60th day. The survival rate decreased on the 75th day and remained stable on the 90th day. Female and twin lambs had a lower survival rate than the male and single lambs. An analysis based on the application groups revealed that a difference in the survival rate between the 15th day and 90th day occurred in the form of a $23 \%$ decrease in the Cronolone group. A sex-based analysis showed that male lambs, which had better survivability until the 60th day, had a sharp decline in survival rate on the 75 th day and fell behind the female lambs. This decline resulted from a higher percentage of deceased male lambs due to a greater number of female lambs born than the male lambs.

Kutluca (2005) reported a survival rate of $67 \%$ for a weaning time of 75 days among Morkaraman lambs in the sponge application group while another researcher (Emsen, 2002) reported a survival rate of $83 \%$ for Morkaraman lambs. The rates achieved by the present study were close to the above rates.

\section{Conclusion}

The analysis of the success rates of estrus synchronization preparations with variable costs in laparoscopic artificial insemination revealed that the highest success rates in terms of the rate of estrus, pregnancy rate, birth rate, and litter sizes were achieved by the use of CIDR intravaginal plastic device. The analysis of the feasibility of a high-cost technology like laparoscopic artificial insemination, when combined with the less expensive estrus synchronization techniques, concluded that the overall success of the program was more important than the costs of estrus synchronization. 
Additionally, it was found in this study which was investigated the stimulation of sheep, one of the most suitable farm animals for organic livestock, with nonsynthetic natural preparations, that the natural progesterone extracted from the roots of a plant called Mexican yam, which was used in Turkey for the first time, formed estrus effectively in sheep.

\section{References}

Ainsworth L, Shrestha JNB. 1983. Effect of type of intravaginal progestagen treatment of estrous response and reproductive performance of ewes. Theriogenology, 19(6): 869-875.

Alaçam E, Vural R, Küplülü Ş, Salmanoğlu R, Akçaba N. 2001. The effect on fertility of short intervals lambing in İvesi sheep raised in North Cyprus. Lalahan Hay. Araş. Derg., 41(1): 35-44.

Altın T, Karaca O, Cemal İ. 2003. The Effect of Weaning Age on Growth of Lambs and Milk Production of Dam. Yuzuncu Y1 University Journal of Agricultural Sciences (J. Agric. Sci.) 13(2): 103-111.

Arsoy Başaran D. 1995. Possibility of controlling estrous and increasing fertility by using exogenous hormone in Awassi sheep. PHD Thesis, Graduate School of Natural and Applied Sciences, Ankara.

Aslan FA. 2008. The growth and reproductive performance of different crossbred genotypes of romanov ram and ewe lambs. Master Thesis, Graduate School of Natural and Applied Sciences, Ataturk University, Erzurum, Turkey.

Atsan T, Emsen E, Yaprak M, Dagdemir V, Diaz CAG. 2007. An economic assessment of differently managed sheep flocks in eastern Turkey. Ital.J.Anim.Sci. Vol. 6: 407-414.

Berhan A, Van Arendonk J. 2006. Reproductive performance and mortality rate in Menz and Horro sheep following controlled breeding in Ethiopia. Small Ruminant Research, 63: 297-303

Cardwell BE, Fitch GQ, Crutcher B. 2009. Synchronization of Ewes with Norgestomet Implants. http://www.ansi.okstate. edu/research/1996rr/56.pdf. 2009; (14.04.2009)

Düzgüneş O, Kesici T, Gürbüz F. 1983. Statistical Methods. A.Ü. Zir. Fak. Yay: 861, 229 s, Ankara.

Emsen E. 2002. The Effect of vitamin E+Se and eksogen hormon treatments of reproductive performance of Awassi and Redkaraman sheep, growth and survivability of their lambs. PHD Thesis, Graduate School of Natural and Applied Sciences, Ataturk University, Erzurum, Turkey.

Emsen E, Gimenez Diaz C. 2008. Influences of maternal factors on Sex Ratio. The 37 th International Session of Scientific Communications of The Faculty of Animal Science, Bucharest, Romania

Emsen E, Gimenez Diaz CA, Yaprak M, Koycegiz F, Kutluca M, Aslan FA. 2008. Factors affecting the reproductive performance of fat-tailed ewes inseminated with laparoscopy in the late breeding season. Anim. Reprod. v.5, n.1/2, p.3033, Jan./Jun.

Fukui Y, Ishikawa D, Ishida N, Okada M, Itagak R, Ogiso T. 1999. Comparison of fertility of estrous synchronized ewes with four different intravaginal devices during the breeding season. Journal of Reproduction and Development 45(5): 337-343.

Godfrey RW, Gray ML, Collins JR. 1997.A comparison of two methods of oestrous synchronisation of hair sheep in the tropics. Anim-Reprod-Sci. 47(1-2): 99-106.

G'omez JD, Balasch S, G'omez LD, Martino A, Fern'andez N. 2006. A comparison between intravaginal progestagen and melatonin implant treatments on the reproductive efficiency of ewes. Small Ruminant Research 66: 156-163

Gourley DD, Riese RL. 1990. Laparoscopic Artificial Insemination in Sheep. Veterinary Clinics of North America: Food Animal Practice 6:(3) 615-633.
Kohno H, Okamoto C, Iıda K, Takeda T, Kaneko E, Kawashıma C, Miyamoto A, Fuku1 Y. 2005. Comparison of Estrus Induction and Subsequent Fertility with Two Different Intravaginal Devices in Ewes during the Non-Breeding Season. Journal of Reproduction and Development 51(6): 805-812.

Koyuncu M, Öziş Altınçekiç Ş, Nageye Fİ. 2019. Effects of CIDR, Vitamin A, E + Selenium on Reproductive Performance in Ewes of Anestrus Period. KSU J. Agric Nat. 22(additional number 1): 179-187.

Kutluca M. 2005. The effects of different estrus synchronization regimes on fertility of awassi and redkaraman ewes and groving performance and survivability of their lambs. Master Thesis, Graduate School of Natural and Applied Sciences, Ataturk University, Erzurum, Turkey.

Macías-Cruz U, Ponce-Covarrubias JL, Álvarez-Valenzuela FD, Correa-Calderón A, Meza-Herrera CA, AvendaÑo-Reyes L. 2013. Reproductive efficiency of Pelibuey and Romanov $\times$ Pelibuey ewes synchronized with synthetic progesterone and low doses of PMSG under a hot environment. Czech J. Anim. Sci. 58(12): 546-553.

Masoudi R, Shahneh AZ, Towhidi A, Kohram H, Akbarisharif A, Sharafi M. 2017. Fertility response of artificial insemination methods in sheep with fresh and frozen-thawed semen. Cryobiology 74:77-80.

Milovanovic A, Maksimović N, Barna T, Lazarević L, Delić N. 2013. Laparoscopic Insemination of Sheep in Republic of Serbia. Biotechnology in Animal Husbandry 29(3):449-456.

Minitab Student Handbook 2000. Duxbury Press.

Murali Mohan K. 2017. Comparative study of reproductive efficiency in ewes synchronized with vaginal sponges and CIDR during breeding and non-breeding seasons. The Pharma Innovation Journal 6(4): 75-79

Öziş Altınçekiç Ş, Koyuncu M, Duru S. 2018. Determination of T3, T4 and Cortisol Levels in CIDR applied Kivircik and Karacabey Merino Ewes. Journal of Tekirdag Agricultural Faculty 15(02): 112-118.

Prasad BS, Srinivas M, Naidu GV, Rao VV. 2020. Silicone moulds for morphometric studies on cervical canal of Nellore sheep. The Pharma Innovation Journal; SP-9(9): 172-174.

Santos-Jimenez Z, Martinez-Herrero C, Encinas T, Martinez-Ros P, Gonzalez-Bulnes A. 2020. Comparative efficiency of oestrus synchronization in sheep with progesterone/eCG and progesterone/GnRH during breeding and non-breeding season. Reprod Dom Anim. 00:1-3. https://doi.org/ 10.1111/rda. 13698

Sathe SR. 2018. Laparoscopic Artificial Insemination Technique in Small Ruminants-A Procedure Review. Front. Vet. Sci.; 5, Article 266: 1-9.

Shahat KHEL, Alsafy MAM. 2009. The anatomical structures of sheep cervix and its influence on the transcervical passage of an inseminating catheter into the uterine lumen. Vet. Med. J., Giza. Vol. 57, No.2 :211-222.

Texeira TA, Fonseca JF, Souza-Fabjan JMG, Rezende Carvalheira L, Moura Fernandes DA, Brandão ZF. 2016. Efficiency of different hormonal treatments for estrus synchronization in tropical Santa Inês sheep. Trop Anim Health Prod. 48:545-551.

Ungerfeld R, Rubianes E. 2002. Short term primings with different progestogen intravaginal devices (MAP, FGA and CIDR) for eCG-estrous induction in anestrus ewes. Small Ruminant Research 46: 63-66.

Üstuner B, Gunay U, Nur Z, Ustuner H. 2007. Effects of Long and Short-Term Progestagen Treatments Combined with PMSG on Oestrus Synchronization and Fertility in Awassi Ewes during the Breeding Season. Acta Vet. Brno. 76: 391-397.

Zeleke M, Greyling JPC, Schwalbach LMJ, Muller T, Erasmus JA. 2005. Effect of progestagen and PMSG on oestrous synchronization and fertility in Dorper ewes during the transition period. Small Ruminant Research 56: 47-53.

Zonturlu AK, Aral F, Ozyurtlu N, Yavuzer U. 2008. Synchronization of Estrus Using FGA and CIDR Intravaginal Pessaries during the Transition Period in Awassi Ewes. Journal of Animal and Veterinary Advances 7(9): 1093-1096. 